\title{
Interacting effects of amygdala lesions with chlordiazepoxide and pilocarpine on mouse killing by rats
}

\author{
PATRICIA E. GAY, LARRY S. POTTER, and SHERWOOD 0. COLE \\ Rutgers University, Camden, New Jersey 08102
}

\begin{abstract}
Following lesions of the amygdala, rats previously responsive to the killing-initiating effects of chlordiazepoxide $(7.5 \mathrm{mg} / \mathrm{kg}$ ) either continued to kill when drugged or demonstrated a complete block of the mouse-killing response. These responses to the drug appeared related to the site and extent of lesion damage. However, daily injections of pilocarpine $(7.5 \mathrm{mg} / \mathrm{kg})$, administered beginning on Postsurgical Day 19, initiated killing in most of the amygdala-lesioned rats. Possible interpretations of this finding are discussed.
\end{abstract}

Chlordiazepoxide and pilocarpine are two drugs known to initiate mouse killing in "nonkiller" rats. Repeated injections of pilocarpine can initiate killing in virtually all Holtzman strain rats if the dose is sufficiently high (Wnek \& Leaf, 1973). Single doses of chlordiazepoxide $(2.5-80 \mathrm{mg} / \mathrm{kg})$, on the other hand, initiate killing in only $10 \%-20 \%$ of the same strain rat, and repeated dosing does not substantially increase this percentage (Leaf, Wnek, Gay, Corcia, \& Lamon, 1975). As pilocarpine-induced killing, but not chlordiazepoxide-induced killing, is blocked by centrally active anticholinergic drugs such as atropine and scopolamine (Leaf et al., 1975; Vogel \& Leaf, 1972; Wnek \& Leaf, 1973), pilocarpine may initiate killing via a cholinergic mechanism. The mechanism by which chlordiazepoxide initiates killing is unknown. However, $d$-amphetamine reliably blocks mouse killing induced by both drugs (Gay, Leaf, \& Arble, 1975; Leaf et al., 1975; Vogel \& Leaf, 1972).

Lesions of the amygdala (particularly medial portions) temporarily block killing initiated by pilocarpine (Gay, Cole, Leaf, \& Clark, Note 1). While lesioned animals eventually reinstate killing, it is unclear whether the lesions temporarily decrease sensitivity to the pharmacological action of pilocarpine or whether other time-dependent changes, such as recovery from a "sensori-motor syndrome" (Turner, 1973), account for the eventual recovery of pilocarpine-induced killing.

The present study was designed to explore the following questions: (1) Do amygdala lesions also attenuate the effects of chlordiazepoxide on mouse

This research was supported by USPHS Grant MH21247 to Russell C. Leaf, Patricia E. Gay, and Sherwood O. Cole. Principal Investigators. We are indebted to Michael Hatalovsky for technical assistance throughout the course of the research. Requests for reprints should be sent to Patricia E. Gay. Department of Psychology. Rutgers University, Camden, New Jersey 08102 . killing, and (2) if so, do the same lesions affect sensitivity to pilocarpine?

\section{METHOD}

\section{Subjects}

The subjects were 18 male Holtzman rats $(272-547 \mathrm{~g})$, selected because they killed mice on at least two successive 2 -h tests for mouse killing when given $7.5 \mathrm{mg} / \mathrm{kg}$ chlordiazepoxide IP. All animals were given ad-lib access to Purina Rat Chow and tap water throughout the course of the experiment.

The prey were ICR-derived mice of both sexes.

\section{Procedure}

Following selection, animals were randomly assigned to two surgical groups (amygdala lesions or sham lesions) of equal size $(\mathrm{N}=9$ /group). Electrolytic amygdala lesions (2-mA anodal dc current for $20 \mathrm{sec}$ ) were produced stereotaxically by means of stainless steel electrodes insulated except at the tip. Coordinates for the amygdala (Pellegrino \& Cushman, 1967) were $1.0 \mathrm{~mm}$ posterior to bregma, $4.0 \mathrm{~mm}$ lateral to midline, and $8.0 \mathrm{~mm}$ vertical depth. A rectal cathode completed the circuit. The procedure was the same for sham operates, except that no current was passed following electrode placement.

The animals were then allowed 7 days to recover from surgery before beginning the regimen of drug administration outlined in Table 1. On "blank" days, no testing or drug administration took place.

On each test day, each animal was injected IP with the prescribed drug (dissolved in $1 \mathrm{cc} / \mathrm{kg} .9 \% \mathrm{NaCl}$ ). Fifteen minutes later, a single mouse was placed in the home cage, and each rat was given a 2-h opportunity to kill. Success and latency of kill were recorded. Only one killing test per day was administered.

On the day when both chlordiazepoxide and d-amphetamine were administered, the d-amphetamine injection was given first. followed $30 \mathrm{~min}$ later by the chlordiazepoxide injection. Fifteen minutes later, the 2 -h mouse-killing test began.

At the end of the experiment, the amygdala-lesioned rats were sacrificed and perfused. The brains were removed and fixed in $10 \%$ formaldehyde. They were later frozen, sectioned at 40 micra, stained with cresyl violet, and the lesions verified histologically.

\section{RESULTS}

Amygdala lesions significantly blocked chlordiazepoxide killing, and more sham operates killed at 
Table 1

Schedule of Drug Administration

Test Day

(Relative to Surgery)

Treatment

$\begin{array}{rl}-6--4 & \begin{array}{l}7.5 \mathrm{mg} / \mathrm{kg} \text { chlordiazepoxide } \\ \text { (selection pretests) }\end{array} \\ -3--1 & \text { Blank } \\ 0 & \text { Surgery } \\ +1-+7 & \text { Blank } \\ +8-+12 & 7.5 \mathrm{mg} / \mathrm{kg} \text { chlordiazepoxide } \\ +13-+14 & \text { Blank } \\ +15 & \text { Saline } \\ +16 & 1.5 \mathrm{mg} / \mathrm{kg} \text { d-amphetamine }+ \\ & 7.5 \mathrm{mg} / \mathrm{kg} \text { chlordiazepoxide } \\ +17-+18 & \text { Blank } \\ +19-* & 7.5 \mathrm{mg} / \mathrm{kg} \text { pilocarpine } \\ +21-+22 * & \text { Blank } \\ +23^{*} & \text { Saline }\end{array}$

*Pilocarpine was administered daily until each rat met a criterion of two successive kills. Therefore, the exact timing /relative to surgery) of treatments following pilocarpine treatment varied according to each animal's performance.

least one mouse in the five chlordiazepoxide tests than did amygdala-lesioned animals (two-tailed Fisher exact probability test, $\mathrm{p}<.05)$. While all sham operates $(9 / 9)$ killed at least one mouse $(\bar{X}=3.8$ kills/rat), only four out of nine amygdala-lesioned animals did so. The amygdala-lesioned animals that killed (amygdala-killers), however, did so consistently $(\bar{X}=4.75 \mathrm{kills} / \mathrm{rat})$, in contrast to the five other amygdala-lesioned animals that never made a single kill (amygdala-nonkillers). While the amygdalakillers killed more slowly than the sham operates on Test $1 \mathrm{l} t=2.33$, df $=10, \mathrm{p}<.05, \log$ transformation), they attained comparable latencies on the remaining tests.

When administered saline on Test Day +15 , three out of four amygdala-killers and four out of nine sham operates killed mice, suggesting that for these animals killing had become independent of drug administration. None of the amygdala nonkillers killed mice.

d-Amphetamine blocked killing in four out of nine sham operates and in one out of four amygdala-killers. For the remaining animals in these groups, the latency to kill was significantly lengthened (paired $\mathrm{t}=4.11, \mathrm{df}=7, \mathrm{p}<.01, \log$ transformation) compared to their performance on the last chlordiazepoxide test. All animals (except one sham operate) which killed under the drug combination had previously killed when administered saline.

Repeated injections of pilocarpine induced mouse killing in all but one animal. All sham operates eventually met the criterion of two successive kills $(\overline{\mathrm{X}}=3.89$ trials to criterion), as did all amygdala killers ( $\bar{X}=4.25$ trials to criterion). Only one amygdala nonkiller failed to kill, and the remaining four animals took an average of 5.6 trials to meet criterion. For animals that killed with both drugs, the latency to kill with pilocarpine was longer than that for chlordiazepoxide (paired $t=3.72, \quad d f=12$, $\mathrm{p}<.01$ ).

When saline was administered following the series of pilocarpine injections, three out of four amygdala-killers killed mice and four out of nine sham operates did so. None of the amygdala nonkillers did so, even though they had previously killed with pilocarpine. Most of the rats killing mice had also killed mice on the first saline test (Test Day +15).

Figure 1 shows representative lesions for the amygdala-killer (Animal 6A) and amygdala nonkiller (Animal 3A) subgroups. In general, both groups showed at least unilateral damage to more medial portions of the amygdala (medial and central nuclei), while amygdala-killers had larger lesions and showed, in addition, damage to more basal portions (cortical, basomedial, and basolateral nuclei) of the amygdala.

\section{DISCUSSION}

Following lesions of the amygdala, animals previously responsive to the killing-initiating effects of chlordiazepoxide either continued to kill when drugged and were indistinguishable from sham operates or demonstrated a complete block of the mouse-killing response. These responses to the drug appeared related to the site and extent of lesion damage. Amydala killers showed extensive damage to medial and basal portions of the amygdala, while amygdala nonkillers had more restricted damage to central and medial portions of the amygdala. These are the same sites reported by Eclancher. Schmitt. and Karli (1975) to be effective in increasing the percentage of rats killing mice in adulthood when lesions were produced at the age of $7-8$ days. As in this study, animals with the larger lesions killed more readily than those with more restricted medial lesions. Taken together, these studies suggest that larger amygdala lesions are less liable to alter mouse killing and may even facilitate it. That most of the amygdala killers in this study killed without drug (saline tests) supports this point of view.

Pilocarpine initiated killing in all but one amygdala-lesioned rat that failed to kill with chlordiazepoxide. These findings suggest that
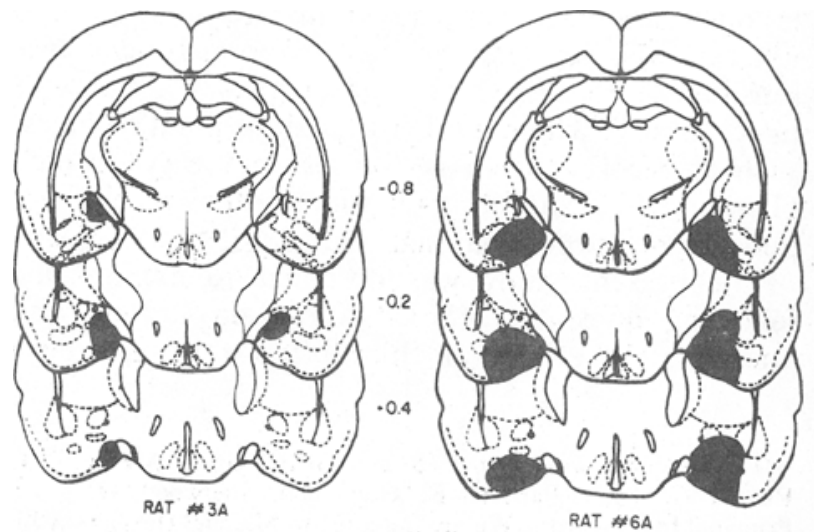

Figure 1. Reconstructions of representative lesions for the amygdala-killer (Animal 6A) and the amygdala-nonkiller (Animal 3A) subgroups. (Figures adapted from Pellegrino \& Cushman [1967]). 
chlordiazepoxide and pilocarpine may initiate mouse killing via different central mechanisms. However, such a suggestion can only be tentative in that the pilocarpine tests began 19 days postsurgery. Animals with lesions of the medial amygdala often assume a killing response several weeks (Turner, 1973) to several months (Eclancher et al., 1975) postsurgery, particularly if they are "primed" by some technique known to induce killing in nonkiller rats (Gay et al., Note 1; Vergnes, 1975). In an attempt to differentiate between these hypotheses, all animals in the present study were given a second series of tive chlordiazepoxide killing tests beginning 6 days after the last pilocarpine test. Of the five amygdala nonkillers, only two killed mice in this series. while all sham operates and amygdala-killers did so. Thus, some amygdala-lesioned rats which killed with pilocarpine failed to kill with chlordiazepoxide regardless of the postsurgical time of chlordiazepoxide administration. Because of the small number of animals in this study, however. these findings are only suggestive, and more research is required to differentiate between these alternative explanations.

All animals killed more slowly with pilocarpine than with chlordiazepoxide, in spite of the fact that the animals were more practiced killers by the time of the pilocarpine series. While this, again, may be suggestive of a different pharmacological action for the two drugs, it may also reflect temporary inhibition as the result of a change in drug state (Gay et al., 1975). Indeed, the latency to kill on the second pilocarpine criterion test was substantially shorter than that on the first test.

The lesions did not appear to alter responsivity to d-amphetamine inhibition of chlordiazepoxide killing. d-Amphetamine has a reported $\mathrm{ED}_{50}$ of $1.5 \mathrm{mg} / \mathrm{kg}$ IP for inhibiting chlordiazepoxide killing (Leaf et al., 1975). The values found here for inhibition of amygdala-killers (1/4) and sham operates (4/9) closely approximate the expected values, considering the small number of animals involved.

\section{REFERENCE NOTE}

1. Gay. P. E., Cole. S. O., Leaf. R. C., \& Clark, L. D. Predatory aggression in amygdalectomized rodents. Paper presented at the Meeting of the American Psychological Association, 1973.

\section{REFERENCES}

Eclancher, F., Schmitt, P., \& Karli, P. Effets de lesions precoces de l'amygdale sur le developpement de l'aggressivite interspecifique du rat. Physiology and Behavior, 1975, 14, 277-283.

Gay, P. E., Leaf, R. C., \& Arble, F. B. Inhibitory effects of pre- and posttest drugs on mouse-killing by rats. Pharmacology, Biochemistry, and Behavior, 1975, 3, 33-45.

Leaf, R. C., WNeK, D. J., Gay, P. E., Corcia, R., \& Lamon, S. Chlordiazepoxide and diazepam induced mouse killing by rats. Psychopharmacologia (Berlin), 1975,44, 23-28.

Pellegrino, L., \& Cushman, A. J. $A$ stereotaxic atlas of the rat brain. New York: Appleton-Century-Crofts, 1967.

TuRner, B. H. Sensorimotor syndrome produced by lesions of the amygdala and lateral hypothalamus. Journal of Comparative and Physiological Psychology, 1973, 82, 37-47.

Vergnes, M. Declenchement de reactions d'aggression interspecifique apres lesion amygdalienne chez le rat. Physiology and Behavior, 1975, 14, 271-276.

VOGEL, J. R., \& LEAF, R. C. Initiation of mouse killing in non-killer rats by repeated pilocarpine treatment. Physiology and Behavior, 1972, 9, 889-892.

WNEK, D. J. \& LEAF, R. C. Effects of cholinergic drugs on preykilling by rodents. Physiology and Behavior, 1973. 10. 1107-1113. 